\title{
Acute Alveolar Hypoxia Increases Bronchopulmonary Shunt Flow in the Dog
}

Ralph L. Warren and Wm. John Powell, Jr. Departments of Surgery and Medicine (Cardiac Unit), Massachusetts General Hospital and Harvard Medical School, Boston, Massachusetts 02114

\begin{abstract}
To study the effects of alveolar hypoxia on canine bronchopulmonary shunt flow, a biventricular bypass preparation was employed. The preparation allowed a constant and sensitive measure of changes in pulmonary venous blood flow. In 16 of 18 dogs with intact bronchial arteries, alveolar hypoxia caused an increase in pulmonary venous return both under conditions of constant pulmonary arterial inflow and under conditions of no pulmonary arterial inflow, suggesting bronchopulmonary shunting. This effect was accompanied by systemic vasodilation despite vagotomy and ganglionic blockade, and was abolished by division of all bronchial vessels. Ibuprofen, $3 \mathrm{mg} / \mathrm{kg}$, and indomethacin, 15 $\mathrm{mg} / \mathrm{kg}$, in dogs with intact bronchial vessels, abolished both the increase in pulmonary venous return and the systemic vasodilatation caused by hypoxia. Thus, alveolar hypoxia directly augments bronchopulmonary flow, most likely through release of one or more vasodilating prostaglandins.
\end{abstract}

\section{Introduction}

The vasoconstrictor response of the pulmonary vasculature to alveolar hypoxia is now well established, and clarification of the mechanism of the response is slowly evolving $(1,2)$. The effects of alveolar hypoxia on the bronchial circulation, however, have not been well characterized. In particular, possible effects on bronchopulmonary anastomotic flow have not been adequately described.

In order to study the effects of alveolar hypoxia on bronchopulmonary shunt flow, all independent variables affecting this flow must be considered and, where possible, controlled. The major hemodynamic and neural determinants of bronchopulmonary flow have been studied by several groups over the past four decades. The majority of investigators (3-9) have found that systemic arterial pressure, independent of cardiac output, is one of the principal factors determining bronchopulmonary shunt flow. Although the exact anatomic location of the connections between the bronchial and pulmonary circulations is a subject of some controversy $(10,11)$, all agree that the pulmonary arterial and venous pressures, reflecting the "outflow pressure" of the bronchopulmonary anastomoses, are also principal determinants. Systemic venous pressure, as a determinant of the outflow pressure of the bronchial veins, can modify the fraction of bronchial arterial blood that flows into the broncho-

Address reprint requests to Dr. Powell, Cardiac Unit-ACC-3A, Massachusetts General Hospital, 15 Parkman Street, Boston, MA 02114.

Received for publication 20 September 1985 and in revised form 17 December 1985.

J. Clin. Invest.

(C) The American Society for Clinical Investigation, Inc. 0021-9738/86/05/1515/10 \$1.00

Volume 77, May 1986, 1515-1524 pulmonary anastomoses $(5,6)$. Increasing intrapulmonary pressure and positive end-expiratory pressure can decrease bronchopulmonary flow independent of primary changes in intravascular pressures $(7,9,12-15)$. Sympathetic nerve stimulation has been shown to decrease total bronchial arterial flow $(12,16$, 17) even though it may increase bronchopulmonary shunt flow (presumably through constriction of bronchial veins) (17), whereas vagal stimulation increases total bronchial flow with unknown effects on bronchopulmonary flow $(7,12)$.

Control of systemic blood gases is also important, because their effects on the bronchial circulation are not clear. Systemic hypoxemia has been reported to increase (18-20) or decrease $(21,22)$ total bronchial flow, and systemic hypercarbia has been reported to increase $(12,19,22)$, not change $(5)$, or decrease (21) bronchial flow.

Previous studies of the effects of alveolar hypoxia on the bronchial circulation are limited and conflicting. Bruner and Schmidt (12) reported that alveolar hypoxia increased total bronchial arterial flow in open-chest dogs, whereas Baile and Pare (22) found the opposite effect; neither group studied bronchopulmonary shunt flow. Williams and Towbin (4) found that alveolar hypoxia slightly decreased bronchopulmonary flow in one intact dog and in two whose left pulmonary artery had been ligated months before; Lilker and Nagy (18) then reported that alveolar hypoxia increased the bronchial flow taking part in gas exchange in dogs several months after left pulmonary artery ligation.

The bronchial circulation is thought to serve primarily as a source of nutrition for the lung parenchyma as well as for the bronchi. In conditions such as consolidation, alveolar edema, and atelectasis, in which the alveolar structures are deprived of inspired gases, the only sources of oxygen are mixed venous and bronchial arterial blood. Because there is only a limited amount of oxygen available for use in mixed venous blood, it might be reasoned that during alveolar hypoxia the bronchial flow to the pulmonary parenchyma should increase. In particular, that portion of bronchial arterial flow that supplies the most distal portions of the bronchial and pulmonary vascular trees-the bronchopulmonary anastomotic flow $(10,11)$-should increase.

The object of the present study was to examine the effects of alveolar hypoxia alone, independent of changes in systemic hemodynamics, systemic blood gases, and neural effects, on the bronchopulmonary anastomotic flow in the lungs of normal dogs. A technique was utilized that allowed detection and quantitation of small changes in pulmonary venous blood flow.

\section{Methods}

A total of 24 adult mongrel dogs of both sexes weighing between 19 and $32 \mathrm{~kg}$ (mean weight $22 \pm 2 \mathrm{~kg}$ ) were anesthetized with chloralose (90 $\mathrm{mg} / \mathrm{kg}$ i.v.) and urethane $(900 \mathrm{mg} / \mathrm{kg}$ i.v.). After intubation with a cuffed endotracheal tube, ventilation was maintained with a Harvard volume respirator (Harvard Apparatus Co., Inc., S. Natick, MA) with a tidal volume of $15 \mathrm{ml} / \mathrm{kg}$, a rate of $12-15$ breaths $/ \mathrm{min}$, and $2 \mathrm{~cm} \mathrm{H}_{2} \mathrm{O}$ positive 
end-expiratory pressure. The lungs were inflated every 20-40 min to a pressure of $15-25 \mathrm{cmH}_{2} \mathrm{O}$ to minimize atelectasis. Inspired gas was either $\mathrm{O}_{2}$-enriched room air or, for alveolar hypoxia, either $98 \% \mathrm{~N}_{2} / 2 \% \mathrm{CO}_{2}$ or $95 \% \mathrm{~N}_{2} / 5 \% \mathrm{CO}_{2}$.

A biventricular bypass preparation via median sternotomy, illustrated schematically in Fig. 1, was used. The right atrium (RA) ${ }^{1}$ and right ventricle (RV) were drained by gravity into a bubble oxygenator ("Right reservoir”) (Bentley Bio 10, Bentley Laboratories, Inc., Irvine, CA) via a large-bore cannula with multiple side holes inserted through the atrial appendage. This blood was returned with a roller pump ("PA pump") to the pulmonary artery (PA) at a constant rate throughout each experiment via a cannula inserted through a purse string in the $R V$ outflow tract into the main PA. A heavy ligature was tied around the cannula in the PA to prevent direct communication between the RV and the PA, and an arterial filter (40- $\mu \mathrm{m}$ pore size, Pall Corp., Glen Cove, NY) was interposed between the right reservoir and the PA pump. The left heart was drained via a large-bore cannula with multiple side holes inserted into the left atrium (LA) through a purse string in the left ventricular (LV) apex. Pulmonary venous return was directed through this cannula into a 100-cm-tall, $4 \mathrm{~cm}$ in diam cylinder ("LA column"). The height above the heart of an open-ended side tube off the LA drainage cannula determined the left atrial pressure, and was held constant throughout each experiment. The blood was pumped with a roller pump ("LA pump") from a side hole in the bottom of the cylinder into a second oxygenator ("Left reservoir"), and finally, from this left reservoir into the femoral arteries via a third roller pump ("Femoral pump"). The aorta was cross-clamped at the level of the coronary ostia to eliminate aortic regurgitation, coronary blood flow, and $\mathrm{LV}$ contraction. Two additional roller pumps were used to transfer blood between the two reservoirs if needed.

The PA perfusion was $82 \pm 15(\mathrm{SEM}) \mathrm{ml} / \mathrm{kg} \cdot \mathrm{min}$ and was kept constant in each animal; in two dogs this flow was increased by $70 \%$ as an independent experimental variable. The LA pump rate from the LA column was adjusted at the beginning of each control period so that the volume of blood in the LA column was constant, i.e., outflow was adjusted to match inflow. Thereafter and throughout each experimental run the LA pump rate was kept constant. The hydrostatic pressure of the column of blood in the cylinder was continuously monitored with a pressure transducer near the bottom of the column; this provided a sensitive (within $1 \mathrm{ml}$ ) measure of the changes in blood volume contained in the column. Changes in the volume of blood in the LA column reflected changes in pulmonary venous return ("LA return"), which in turn were determined by the net of $(a)$ changes in pulmonary intravascular blood volume, $(b)$ changes in pulmonary extravascular fluid content, and (c) changes in bronchopulmonary shunt flow.

It was found that all of the roller pumps (Cardiovascular Instruments Corp., Wakefield, MA, and Sarns, Inc., Ann Arbor, MI) were both preload- and afterload-sensitive, even with the roller heads being occlusive. The magnitude of this effect was not great: the LA pump, for example, would pump 2,004, rather than $2,000, \mathrm{ml} / \mathrm{min}$, if the height of the column of blood in the LA column was increased $20 \mathrm{~cm}$. This was a large enough effect, however, to interfere with the measurements in the present study. Therefore the LA pump and the LA reservoir were placed on a stand the height of which off the floor could be continuously varied with an automobile jack to maintain constant the relation among the heights of the blood level in the LA column, the LA pump, and the left reservoir. The afterload and preload sensitivities of the PA pump, on the other hand, were found not to be significant over the range of PA pressures and right reservoir volumes encountered.

Approximately 5 liters of blood obtained from two large donor dogs was used to prime the perfusion system. Additional chloralose and urethane (up to a total of 150 and $1,500 \mathrm{mg} / \mathrm{kg}$, respectively) were administered after initiation of bypass. Whenever additional anesthetic was added, a period of at least $\mathbf{3 0} \mathrm{min}$ was allowed for equilibration before

1. Abbreviations used in this paper: LA, left atrium; LV, left ventricle; PA, pulmonary artery; RA, right atrium; RV, right ventricle.

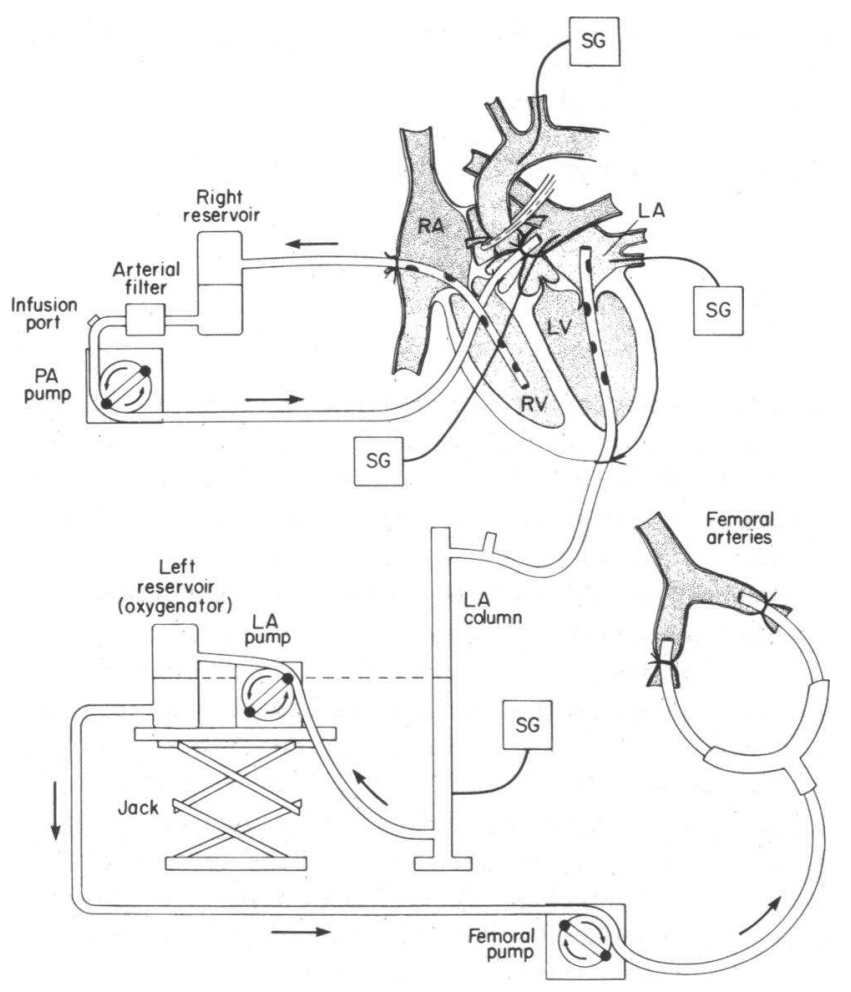

Figure 1. Schematic diagram of the experimental preparation. See text for details. LA, left atrium; LV, left ventricle; PA, pulmonary artery; $R A$, right atrium; $R V$, right ventricle; $S G$, strain gauge pressure transducer.

collection of any experimental data. Blood temperature was kept between 37 and $37.5^{\circ} \mathrm{C}$ with a heat exchanger circulating to the two reservoirs. Simultaneous blood gases from the PA, LA, and femoral arteries were determined at least every $10 \mathrm{~min}$, and more frequently during experimental manipulations of the inspired gases. Blood in the right reservoir was not oxygenated or ventilated; thus the blood pumped into the PA was mixed venous blood. Blood in the left reservoir was oxygenated with a mixture of $100 \% \mathrm{O}_{2}$ and $95 \% \mathrm{O}_{2} / 5 \% \mathrm{CO}_{2}$ to keep the systemic arterial $\mathrm{PO}_{2}>150 \mathrm{mmHg}$ and the $\mathrm{PCO}_{2}$ and $\mathrm{pH}$ within physiologic range $\left(\mathrm{PCO}_{2}\right.$ between 34 and $46 \mathrm{mmHg}$, and pH between 7.34 and 7.46). The preparation was stable for $\sim 5 \mathrm{~h}$.

All vascular pressures were monitored via saline-filled 19-gauge butterfly tubing (Abbott Laboratories, Inc., North Chicago, IL) $15 \mathrm{~cm}$ in length, connected to Gould disposable pressure transducers (Gould Inc., Oxnard, CA). The PA pressure line was inserted through a purse string in the main PA 1-2 cm distal to the tip of the perfusion cannula. The aortic pressure line was inserted through the left internal mammary artery into the aortic arch, and the left atrial pressure line was inserted through the tip of the atrial appendage. Airway pressure was monitored with a transducer directly connected to a side hole in the endotracheal tube. All pressures were continuously recorded on a Hewlett-Packard 7700 eight-channel recorder (Hewlett-Packard Co., Palo Alto, CA).

Cervical vagotomy was accomplished in all animals by simple transection of both vagus nerves $\sim 5 \mathrm{~cm}$ below the level of the thyroid. Ganglionic blockade, when used, was produced by the administration of $5 \mathrm{mg} / \mathrm{kg}$ mecamylamine into the perfusion system. Ibuprofen, 3 $\mathrm{mg} / \mathrm{kg}$ (as sodium ibuprofenate) was given to four dogs by infusion into the right reservoir over $10 \mathrm{~min}$. (Ibuprofen was kindly supplied by Upjohn Co., West Sussex, England). Indomethacin (crystalline, Sigma Chemical Co., St. Louis, MO), $15 \mathrm{mg} / \mathrm{kg}$, dissolved in $100 \mathrm{ml}$ of phosphate buffer at $\mathrm{pH} 8$, was given to two other dogs by the same route. Drugs were infused into the PA with a Harvard infusion pump just proximal to the 
PA pump so that the infusion flow would not alter the total PA flow rate.

In six dogs the bronchial vessels were divided and all collateral sources of bronchopulmonary blood flow were eliminated by careful dissection of the posterior mediastinum through a right thoracotomy prior to median sternotomy. The distal $8 \mathrm{~cm}$ of trachea, the carina, and the bronchi were separated from all posterior structures. The trachea was circumferentially isolated just above the carina, and the pleuropericardial reflections on the hila were divided with electrocautery. Assessment of the completeness of the elimination of bronchopulmonary flow was made at the end of the experiment in five of these dogs by infusing silastic under a pressure of $150-200 \mathrm{mmHg}$ into the thoracic aorta after clamping the arch vessels and the descending aorta at the diaphragm. In two of the five dogs a very small amount of silastic was found to pass into the left upper lung lobe through tiny pleural vessels that had escaped division. In the remainder there was no silastic found in the lung parenchyma, and in none of the five was any silastic found in the main PA or the LA. In contrast, in two dogs whose bronchial vessels were intact, there was extensive filling of the lung vasculature with silastic, and large amounts of silastic were found in both the main PA and the LA.

At the end of each experiment a careful dissection of the lungs and heart was performed. No cases of patent foramen ovale, patent ductus, or any other abnormal systemic-pulmonary or left heart-right heart communication were found.

In order to estimate the total pulmonary intravascular blood volume, in four dogs the systemic circulation was discontinued, and 1 min later the PA and LA pumps were simultaneously stopped. The PA cannula was cross-clamped at its entrance into the RV outflow tract at the same time. Then air was gently blown into the main PA via the PA pressure catheter to displace any remaining intravascular blood. After correcting for the volume of blood contained in the LA, LV, and LA drainage cannula, the amount of blood drained into the LA column during this maneuver represented a gross estimate of pulmonary blood volume.

Statistical analysis of the changes in blood gases with alveolar hypoxia (Table I) was done using a two-sample, single-tailed $t$ test. Statistical significance of the changes in PA and aortic pressures and LA return was determined by analysis of variance and covariance from an extrapolated baseline. Straight lines were fit to the 11 distinct, equally spaced points in each 10-min control period, and variances in the estimated regression lines were computed for each minute post control. The standard estimate for variances in the prediction of a population regression line was employed (23). These minute-by-minute variance estimates, which result in hyperbolic confidence belts around the regression lines, were then pooled across all the experimental runs for each intervention at each minute using the standard method for pooling variance estimates from independent sources (23). The pooled minute-by-minute variance estimates were then used to construct confidence limits (i.e., \pm 1 SEM) about the $x$-axis of hypothetical zero change in the parameter under study. At minutes 4,5 , and 10 the variances thus estimated were added to the variance about the experimental curves at the same time points to construct a two-sample, double-tailed $t$ test of the null hypothesis of zero change of the experimental parameter. Significance was assumed only if $P<0.05$.

\section{Results}

In 16 of the 18 dogs with intact bronchial vessels, ventilation with an hypoxic gas mixture caused an increase in LA flow that persisted as long as the hypoxic mixture was administered. A recorder tracing from a representative experiment is shown in Fig. 2, and the mean data from all experiments are shown in Fig. 3. In all figures, the slopes of the LA return curves represent the LA flow rates relative to the control periods: a positive slope reflects a relative increase, and a negative slope a relative decrease, in LA flow rate. The LA flow began to rise usually within 1-2 min of changing the inspired gas from high to zero $\mathrm{F}_{\mathrm{I}} \mathrm{O}_{2}$ (fractional concentration of oxygen in the inspired gas). It took $0.5-$ $1 \mathrm{~min}$ for the $\mathrm{LA}$ blood $\mathrm{PO}_{2}$ to fall below systemic venous levels, probably owing to the time required for alveolar gas mixing, but by $1.5 \mathrm{~min}$ this level had been reached in all cases (see Table I). The LA flow rate increased by a mean of $3.5 \pm 0.7 \mathrm{ml} / \mathrm{min}$ (range $1.2-11.1 \mathrm{ml} / \mathrm{min})(P<0.001)$, shown by the increase in slope of the LA return curve in Fig. 3 from the control slope of zero. It remained elevated for the entire period of alveolar hypoxia, regardless of the absolute duration, for all times studied (10-25 min). Fig. 3 shows the mean data from the first $10 \mathrm{~min}$ of each experiment, in that $10 \mathrm{~min}$ was the minimum duration of hypoxia studied. Fig. 4 shows the results from a trial lasting 25 min: note that the LA return curve retains its positive slope for the entire period of hypoxia. As shown in Figs. 2-5, as soon as the inspired $\mathrm{F}_{1} \mathrm{O}_{2}$ was increased back to high $\mathrm{O}_{2}$, the LA return began to decline, reflecting a decrease in the LA flow rate to below the control rate, indicated by the negative slope of the LA return curves during recovery.

A second effect of alveolar hypoxia seen in Figs. 2 and 3 is best illustrated in Fig. 5. After a latent period of 1-3 min after the onset of alveolar hypoxia, the systemic arterial pressure at constant systemic flow began to decrease, indicating systemic vasodilatation. The mean decrease in arterial pressure was

Table I. Blood Gases with Alveolar Hypoxia

\begin{tabular}{|c|c|c|c|c|}
\hline & Before hypoxia & $1.5 \mathrm{~min}$ of hypoxia & $10 \mathrm{~min}$ of hypoxia & 2 min after hypoxia \\
\hline \multicolumn{5}{|c|}{$\mathrm{PO}_{2}(\mathrm{mmHg})$} \\
\hline PA & $45 \pm 3$ & $45 \pm 3$ & $41 \pm 2$ & $41 \pm 2$ \\
\hline LA & $365 \pm 31$ & $40 \pm 3^{*}$ & $36 \pm 4^{*}$ & $290 \pm 22$ \\
\hline Art & $397 \pm 36$ & $295 \pm 37 \ddagger$ & $261 \pm 45 \ddagger$ & $345 \pm 43$ \\
\hline \multicolumn{5}{|c|}{$\mathrm{PCO}_{2}(\mathrm{mmHg})$} \\
\hline PA & $43.7 \pm 2.3$ & $43.4 \pm 2.3$ & $43.6 \pm 3.2$ & $43.4 \pm 3.0$ \\
\hline LA & $38.3 \pm 2.1$ & $38.1 \pm 2.2$ & $37.2 \pm 2.7$ & $38.0 \pm 2.9$ \\
\hline Art & $38.1 \pm 1.8$ & $38.0 \pm 1.8$ & $38.5 \pm 2.3$ & $38.3 \pm 2.0$ \\
\hline \multicolumn{5}{|l|}{$\mathrm{pH}$} \\
\hline PA & $7.33 \pm 0.06$ & $7.34 \pm 0.06$ & $7.33 \pm 0.06$ & $7.34 \pm 0.06$ \\
\hline LA & $7.42 \pm 0.08$ & $7.43 \pm 0.08$ & $7.44 \pm 0.09$ & $7.43 \pm 0.08$ \\
\hline Art & $7.43 \pm 0.06$ & $7.43 \pm 0.06$ & $7.42 \pm 0.07$ & $7.43 \pm 0.07$ \\
\hline
\end{tabular}

All data are given as mean \pm SEM. $n=58$ trials in 24 dogs. Art, systemic arterial. ${ }^{*} P<0.001 . \quad ¥ P<0.05$. 


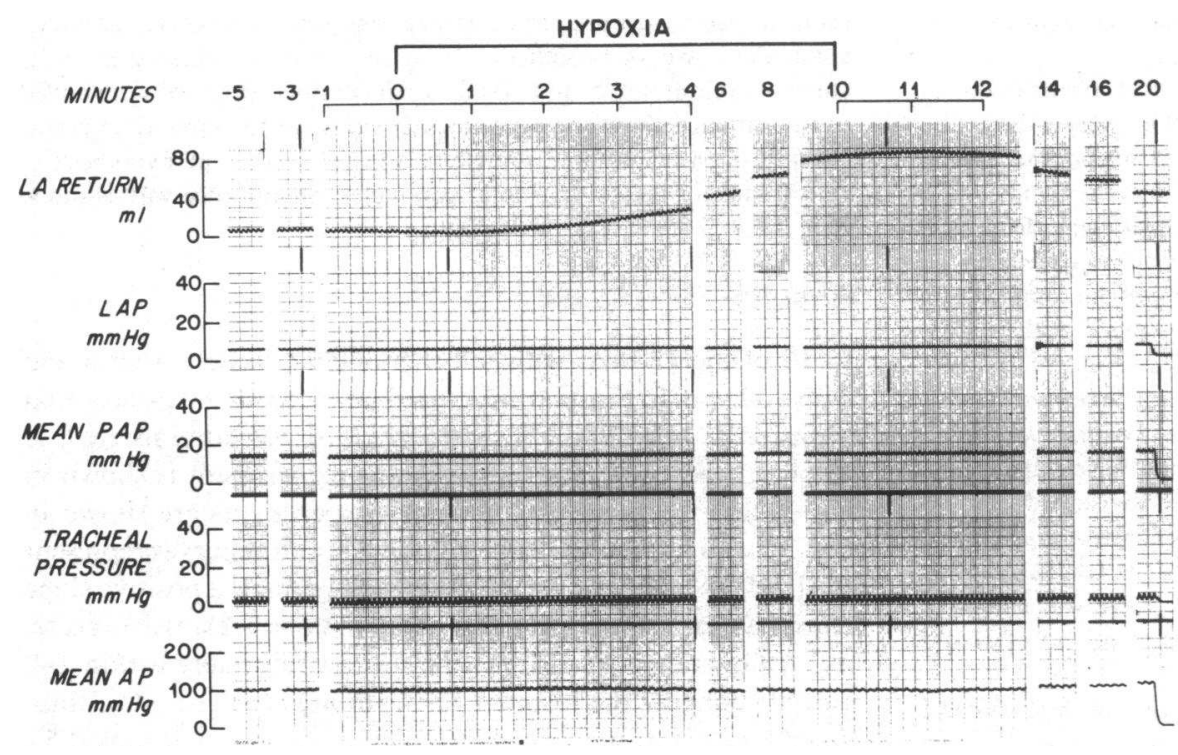

Figure 2. Actual tracing from a representative experiment, presented in segments in order to include the entire period of interest. Alveolar hypoxia, lasting $10 \mathrm{~min}$, started at time 0 . All pressures are electronic means. PAP, pulmonary artery pressure; AP, aortic pressure; LA, left atrium; LAP, left atrial pressure.

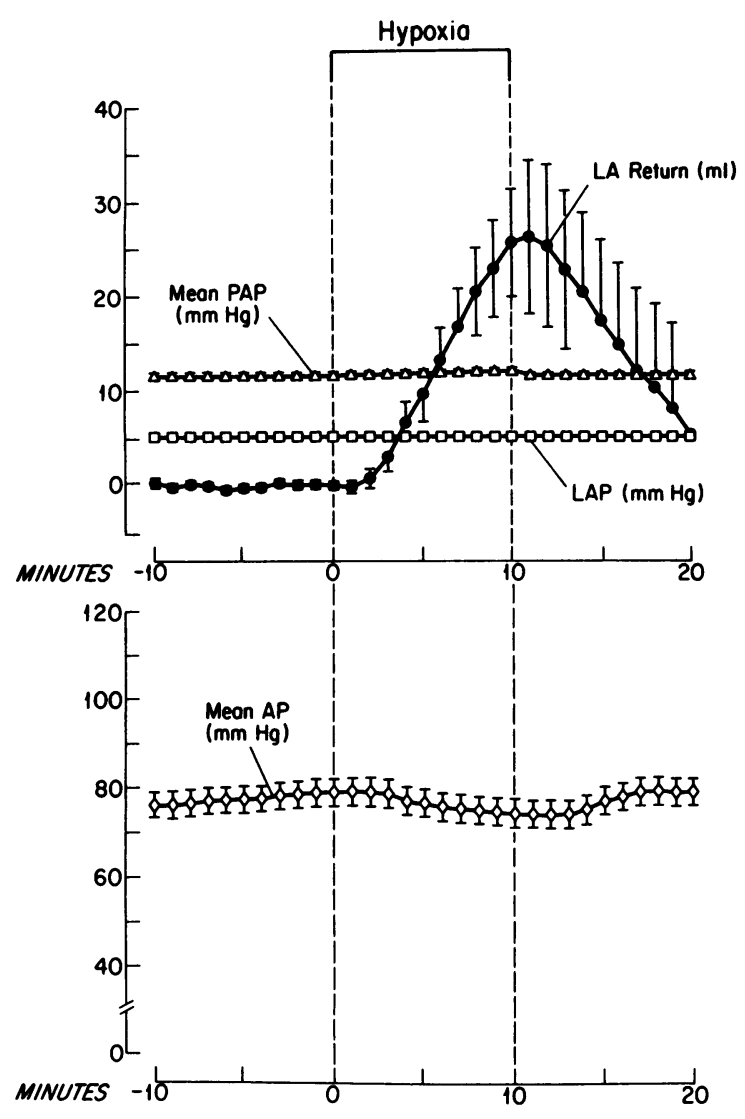

Figure 3. Mean data from all trials with the bronchial vessels intact (except the four trials in the last two dogs before the addition of indomethacin, in all of which a similar response occurred): 37 trials in 16 dogs for the ten minutes of hypoxia; 31 trials in 16 dogs for the recovery period (in the other six trials the PA and LA pumps were turned off to determine persistent LA return). Abbreviations as in Fig. 2. All values are mean \pm SEM, except for LA pressure which was maintained constant. "Hypoxia" signifies alveolar hypoxia. The changes in LA return are significant at minutes 4 through $10(P<0.001)$, and the changes in AP are significant at minutes 5 through $10(P<0.001)$.
$6.2 \pm 1.1 \mathrm{mmHg}(P<0.001)$. It occurred despite unchanged systemic blood $\mathrm{PO}_{2}, \mathrm{PCO}_{2}$, and $\mathrm{pH}$, and despite prior vagotomy and ganglionic blockade. The arterial pressure recovered back to control values over a period of several minutes after cessation of alveolar hypoxia, again with a lag period of 2-4 min. These lag periods corresponded closely to the circulation time between the pulmonary and systemic circuits: because of the presence of two reservoirs (the LA column and the left oxygenator) between the LA and the systemic circulation, it took this amount of time for blood to travel between the two. This effect is illustrated in

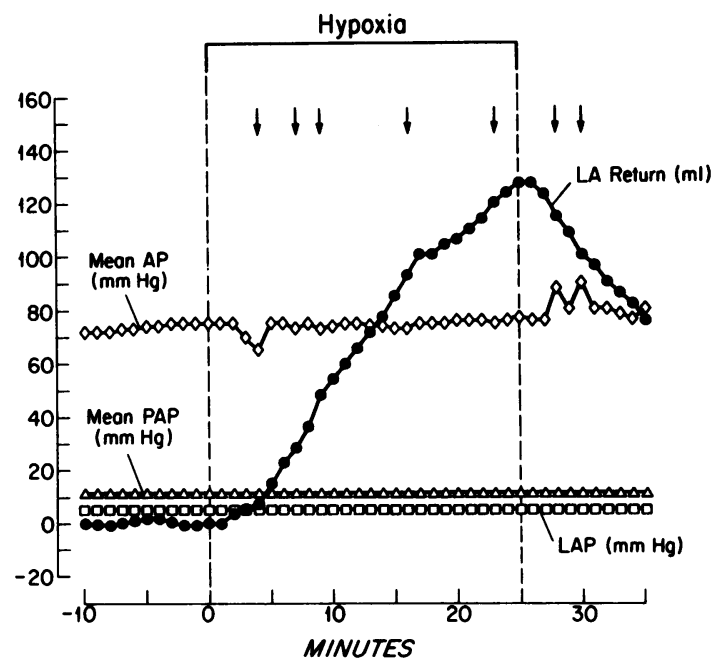

Figure 4. Plot of data from a single experimental trial, bronchial vessels intact, in which alveolar hypoxia was maintained for $25 \mathrm{~min}$. AP was also maintained approximately constant by changing the femoral pump rate at the arrows, increasing the rate during the period of hypoxia, and decreasing it during recovery. Abbreviations as in Fig. 2. Note that (a) LA return continues to increase throughout the prolonged period of alveolar hypoxia, and $(b)$ the total volume increase in LA return is $\sim 125 \mathrm{ml}$. In four other dogs, experimental trials in which the duration of hypoxia was extended to 20-25 min showed total volume increases ranging from 100 to $200 \mathrm{ml}$. 


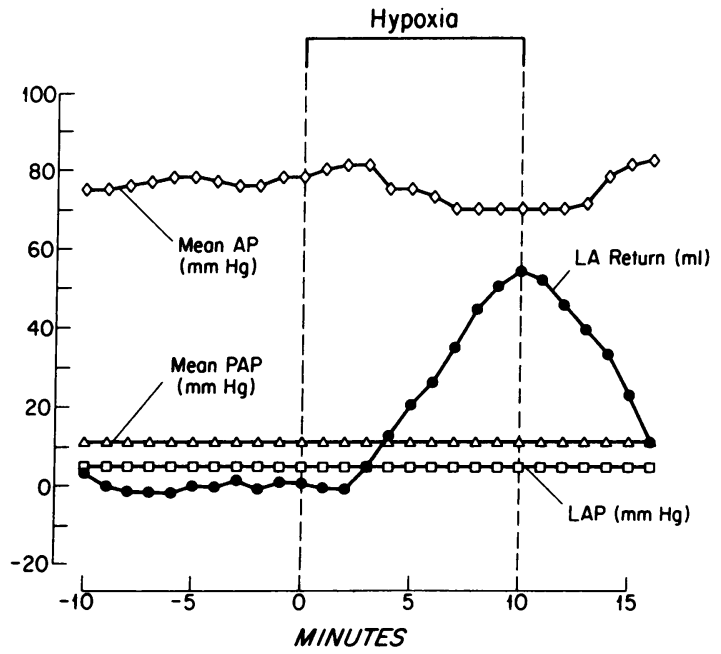

Figure 5. Plot of data from a single experimental trial, bronchial vessels intact, with alveolar hypoxia beginning at time 0 and ending after 10 min. Abbreviations as in Fig. 2. Note the timing of the start of the increase in LA return and the start of the fall in AP.

Fig. 6, in which the effects of norepinephrine injected into the PA are seen to be immediate in the pulmonary circuit, but delayed about 1-2 min in the systemic circulation. It should be noted, moreover, that the increase in LA flow with alveolar hypoxia occurred despite this decrease in arterial pressure, one of the main determinants of bronchial arterial flow. In four dogs, the data from one of which are presented in Fig. 4, the systemic pressure was kept approximately constant by increasing the systemic perfusion rate as needed (indicated by the arrows). It will be seen that the LA flow rate was increased by alveolar hypoxia under conditions of either constant systemic pressure or constant systemic perfusion.

Out of a total of 41 trials in 18 dogs, an increase in LA flow in response to alveolar hypoxia occurred in 33 . In three dogs,

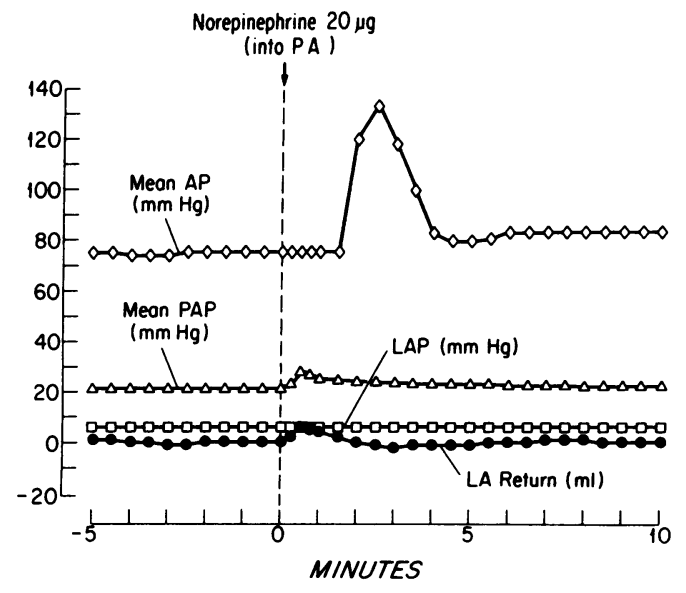

Figure 6. The effects of norepinephrine, 20- $\mu \mathrm{g}$ bolus, injected into the PA perfusion cannula at time 0 , illustrating the circulation time between the pulmonary and systemic circuits. Abbreviations as in Fig. 2. The systemic effects are seen to be delayed $1 \frac{1 / 2}{2} \mathrm{~min}$ after the pulmonary effects. These data are from a dog whose bronchial vessels were divided; exactly similar results were obtained in dogs with intact bronchial vessels. after an initial trial in which this typical response was not seen, subsequent trials did demonstrate an increase in LA flow with alveolar hypoxia. Two additional dogs did not respond with an increase in LA flow in any of a total of five trials. There was no consistent identifiable factor accounting for the lack of response in these animals.

Two additional effects of alveolar hypoxia deserve attention. First, there was no change in intratracheal pressure in response to alveolar hypoxia in any of the experiments. Because the chest remained open, this indicated that there was no change in transpulmonary pressure. Second, and more importantly, there was no significant increase in PA pressure with alveolar hypoxia. This is illustrated in Figs. 2-5, and held true with control PA pressures ranging from 8 to $16 \mathrm{mmHg}$. In that LA pressure and PA flow were held constant, this indicated that there was no significant pulmonary vasoconstriction.

Because the hypoxia-induced increase in LA flow and systemic vasodilatation were unassociated with any significant pulmonary hypoxic pressor response, the presence of a circulating vasodilating substance was suspected. Therefore four dogs were given ibuprofen, $3 \mathrm{mg} / \mathrm{kg}$, into the right (systemic venous) reservoir. As shown in Table II, ibuprofen administration alone caused both the PA and systemic arterial pressures to rise steadily over 20 min, while the LA flow rate decreased. Furthermore, as shown in Fig. 7, alveolar hypoxia after ibuprofen caused a significant rise in PA pressure in all dogs $(P<0.002)$, accompanied by a lack of significant effects on both LA flow and systemic arterial pressure (NS). Again there was no detectable effect on intratracheal pressure. To make certain that these were not nonspecific effects of ibuprofen, indomethacin, $15 \mathrm{mg} / \mathrm{kg}$ was given to an additional two dogs in the same manner, with the same result. The data from a single trial before, and from a single trial after indomethacin obtained from one of these dogs are shown in Fig. 8; the results from all the other trials (a total of four trials before and four trials after indomethacin) in both dogs are similar to those shown.

The effects of ganglionic blockade were examined by comparing the results obtained in eight dogs without mecamylamine to those in the other eight with mecamylamine. As shown in Table III, there were no signficant differences between the two groups in either LA flow changes or systemic arterial and PA pressure changes.

The effects of increasing inspired $\mathrm{PCO}_{2}$ in addition to decreasing $\mathrm{PO}_{2}$ were examined by comparing the results obtained in three dogs with $95 \% \mathrm{~N}_{2} / 5 \% \mathrm{CO}_{2}$ as the hypoxic gas mixture with the remainder in which $98 \% \mathrm{~N}_{2} / 2 \% \mathrm{CO}_{2}$ was used. (The systemic blood gases were kept constant by varying the gas flows through the oxygenator as needed.) Again, as shown in Table

Table II. Effects of Ibuprofen Administration

\begin{tabular}{llll}
\hline & PAP & AP & $\begin{array}{l}\Delta \text { LA } \\
\text { return }\end{array}$ \\
\hline Before ibuprofen & $m m H g$ & $m m H g$ & $\mathrm{ml} / \mathrm{min}$ \\
20 min after ibuprofen & $13.1 \pm 0.6$ & $85 \pm 7$ & \\
& $21.3 \pm 2.2^{*}$ & $125 \pm 7^{*}$ & $-18 \pm 4^{*}$
\end{tabular}

All data are given as mean \pm SEM. $n=4$.

Abbreviations: PAP, pulmonary artery pressure; AP, aortic pressure; LA, left atrium.

$* P<0.01$. 


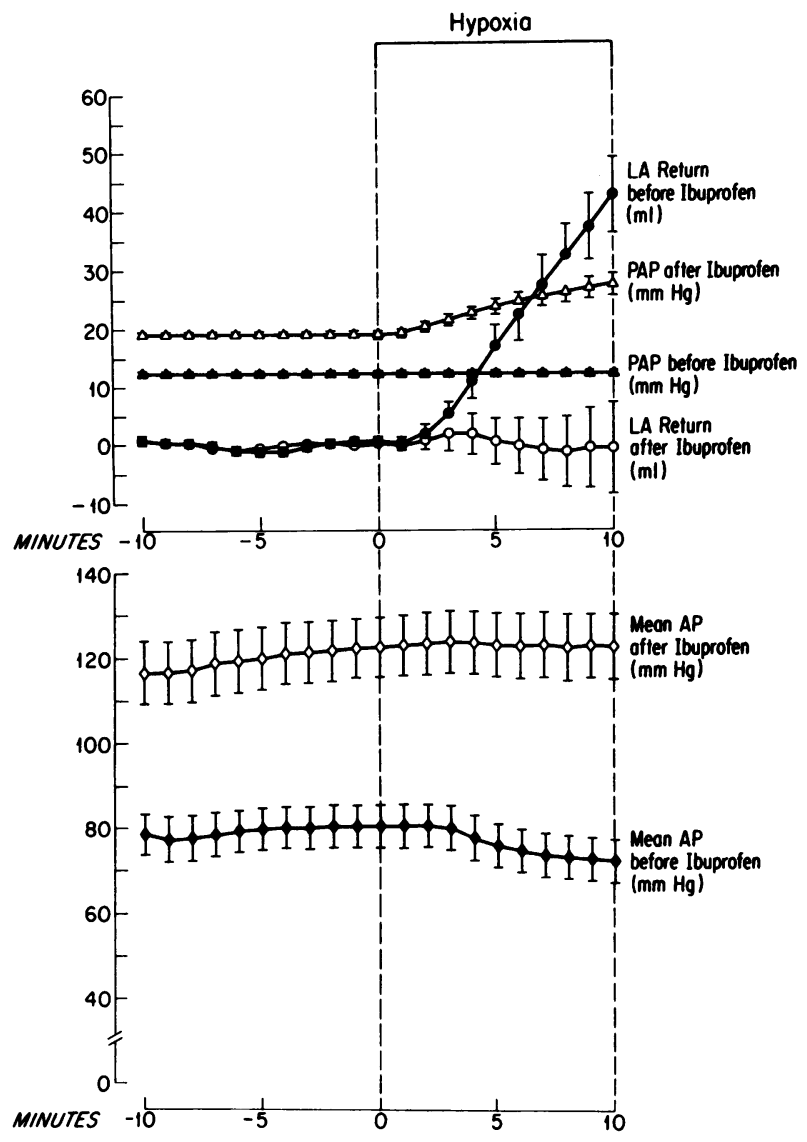

Figure 7. Mean data from all dogs given ibuprofen $(n=4)$. All data are mean \pm SEM. Solid symbols, before ibuprofen; open symbols, after ibuprofen. Abbreviations as in Fig. 2. Alveolar hypoxia begins at time 0 and lasts $10 \mathrm{~min}$. No recovery data are shown because the PA and LA pumps were turned off to determine persistent LA return flow before the termination of the hypoxic challenge. Before ibuprofen, LA return and AP changes are significant $(P<0.01)$, whereas PAP changes are not; after ibuprofen PAP changes are significant $(P$ $<0.002$ ), while LA return and AP changes are not.

IV, there were no significant differences in PA pressure, arterial pressure, or LA flow changes.

The effects of "cardiac output" were examined by increasing the perfusion rate in both the pulmonary and systemic circuits by $70 \%$ in two dogs with the bronchial vessels intact. As shown in Table $\mathrm{V}$, increasing the perfusion rates increased the magnitude of the change in LA flow induced by alveolar hypoxia.

To demonstrate that the LA flow changes caused by alveolar hypoxia represented changes in bronchopulmonary shunt flow, the bronchial vessels and all collateral communications between the systemic and pulmonary circulations were divided prior to biventricular bypass in six dogs; the results are shown in Fig. 9. Alveolar hypoxia in these animals caused no significant change in LA flow rate (NS). Of interest, there was also less systemic vasodilatation than in animals with intact vessels, although there was the same lack of significant pulmonary pressor response.

Further evidence supporting the hypothesis that alveolar hypoxia causes an increase in bronchopulmonary shunt flow was obtained by simultaneously turning off the PA and LA pumps while maintaining the systemic circulation intact. This was done by simultaneously switching off the PA and LA pumps,

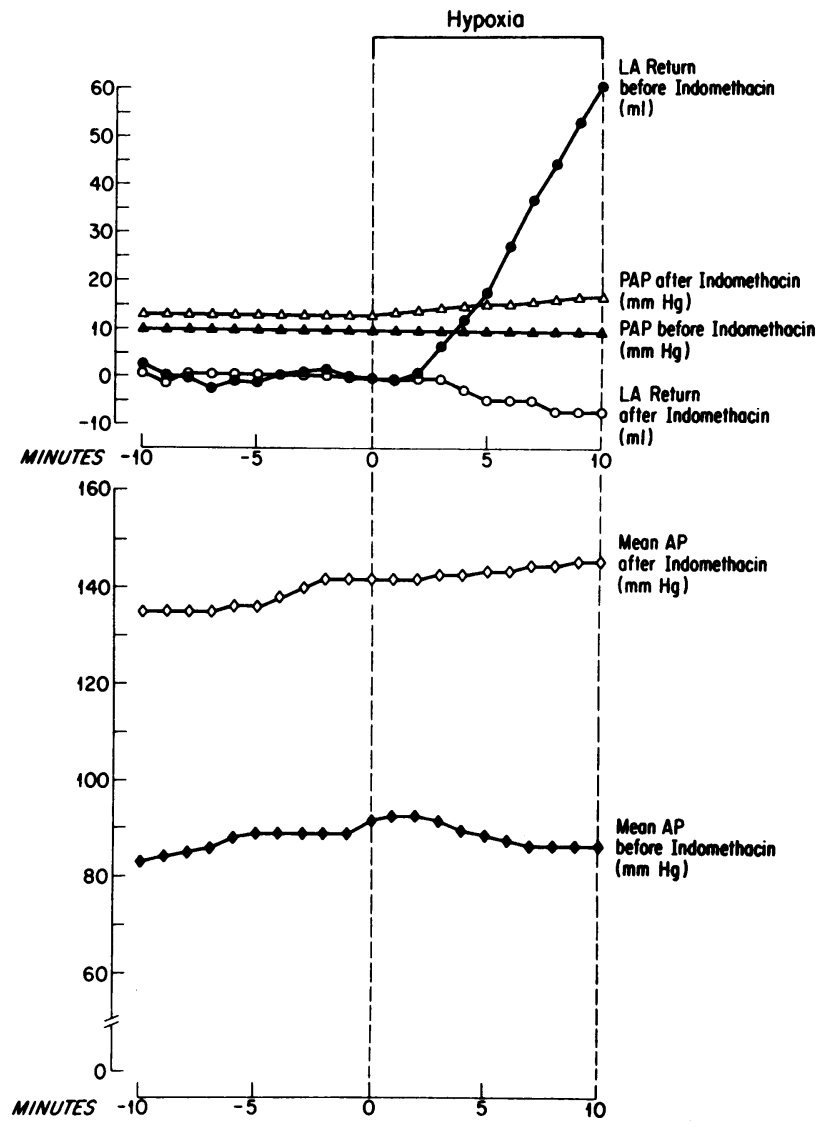

Figure 8. Plot of data from two individual experimental trials in the same dog, one before (solid symbols) and one after (open symbols) indomethacin. Abbreviations as in Fig. 2. No recovery data are shown for the same reason as in Fig. 7.

clamping the PA perfusion cannula, and pumping the systemic venous return from the right reservoir directly into the left reservoir/oxygenator. Under these conditions, after the first minute during which the pulmonary vessels drain most of the blood contained within them, persistent LA blood flow must represent systemic to pulmonary blood flow, i.e., bronchopulmonary shunt flow (in the absence of coronary flow and any abnormal systemicto-pulmonary communications). As shown in Table VI, in six dogs with intact bronchial vessels, the LA return after turning off the PA and LA pumps-i.e., bronchopulmonary anastomotic flow-was $29 \pm 5 \%$ greater after $10 \mathrm{~min}$ of alveolar hypoxia than

Table III. Effects of Ganglionic Blockade

\begin{tabular}{llll}
\hline & \multicolumn{3}{l}{ Changes with alveolar hypoxia } \\
\cline { 2 - 4 } & \multicolumn{4}{c}{$\Delta \mathrm{LA}$ flow rate } & $\Delta \mathrm{AP}$ & $\Delta \mathrm{PAP}$ \\
\hline $\mathrm{ml} / \mathrm{min}$ & $\mathrm{mmHg}$ & $\mathrm{mmHg}$ \\
$\begin{array}{l}\text { With mecamylamine } \\
\quad(n=8)\end{array}$ & $+3.4 \pm 0.8$ & $-8.2 \pm 1.4$ & $+0.2 \pm 0.1$ \\
$\begin{array}{l}\text { Without mecamylamine } \\
(n=8)\end{array}$ & $+3.7 \pm 0.9$ & $-6.4 \pm 2.2$ & $+0.2 \pm 0.1$ \\
\hline
\end{tabular}

All data are given as mean \pm SEM. The differences between the two groups are not statistically significant. Abbreviations as in Table II. 
Table IV. Effects of Inspired $\mathrm{CO}_{2}$

\begin{tabular}{llll}
\hline & \multicolumn{3}{l}{ Changes with alveolar hypoxia } \\
\cline { 2 - 4 } & $\Delta \mathrm{LA}$ flow rate & $\Delta \mathrm{AP}$ & $\Delta \mathrm{PAP}$ \\
\hline & $\mathrm{ml} / \mathrm{min}$ & $\mathrm{mmHg}$ & $\mathrm{mmHg}$ \\
$2 \% \mathrm{CO}_{2}(n=13)$ & $+3.5 \pm 1.1$ & $-7.1 \pm 2.0$ & $+0.2 \pm 0.1$ \\
$5 \% \mathrm{CO}_{2}(n=3)$ & $+3.3 \pm 2.3$ & $-7.0 \pm 4.1$ & $+0.2 \pm 0.1$ \\
\hline
\end{tabular}

All data are given as mean \pm SEM. The differences between the two groups are not statistically significant. Abbreviations as in Table II.

during high $\mathrm{O}_{2}$ ventilation $(P<0.05)$. In four of these, ibuprofen administration not only decreased this persistent LA flow compared with control, but it also abolished the difference between the LA flow with alveolar hypoxia and that with normoxia (NS); the same effects were produced by indomethacin in two dogs (Table VII). In three dogs whose bronchial vessels had been divided, there was no persistent LA flow after turning off the PA and LA pumps, with either alveolar hypoxia or control.

As a rough estimate of the total pulmonary intravascular volume, the volume emptied into the LA column after simultaneous stopping the PA and LA pumps (after prior arrest of the systemic circulation) in four dogs was $4.5 \pm 0.6 \mathrm{ml} / \mathrm{kg}$, or $\sim 100 \mathrm{ml}$ for a $22-\mathrm{kg}$ dog.

\section{Discussion}

The results of these studies demonstrate that alveolar hypoxia directly augments bronchopulmonary blood flow. This effect is due to local mechanisms in that it occurs in the absence of systemic hypoxemia, changes in systemic hemodynamics, and extrinsic neural influences. The bronchopulmonary shunt and its response to hypoxia can be surgically ablated by division of the bronchial vessels, and the magnitude of the response can be quantified.

Several observations support the conclusion that the observed changes in LA return with alveolar hypoxia represented changes in bronchopulmonary shunting, rather than changes in either pulmonary intravascular blood volume or extravascular fluid content. First, the net amount of this increased left atrial return after prolonged hypoxia in several dogs (120-200 ml, e.g, Fig. 4) approached the total pulmonary intravascular volume as estimated in these studies $(100 \mathrm{ml})$ and as measured at comparable pressures by several other investigators (150-300 ml) (24-27). Although hypoxia has indeed been reported to decrease pulmonary intravascular volume $(28,29)$, it is unlikely that volume

Table V. Effects of Cardiac Output

\begin{tabular}{lllll}
\hline & PA flow & Mean PAP & Mean AP & $\begin{array}{l}\Delta \text { LA flow rate } \\
\text { with hypoxia }\end{array}$ \\
\hline \multirow{2}{*}{ Dog 9} & $\mathrm{ml} / \mathrm{kg} \cdot \mathrm{min}$ & $\mathrm{mmHg}$ & $\mathrm{mmHg}$ & $\mathrm{ml} / \mathrm{min}$ \\
& 68 & 10 & 65 & +6.4 \\
$\operatorname{Dog} 11$ & 121 & 15 & 105 & +8.2 \\
& 104 & 8 & 65 & +3.1 \\
& 176 & 12 & 100 & +10.9
\end{tabular}

Abbreviations as in Table II.

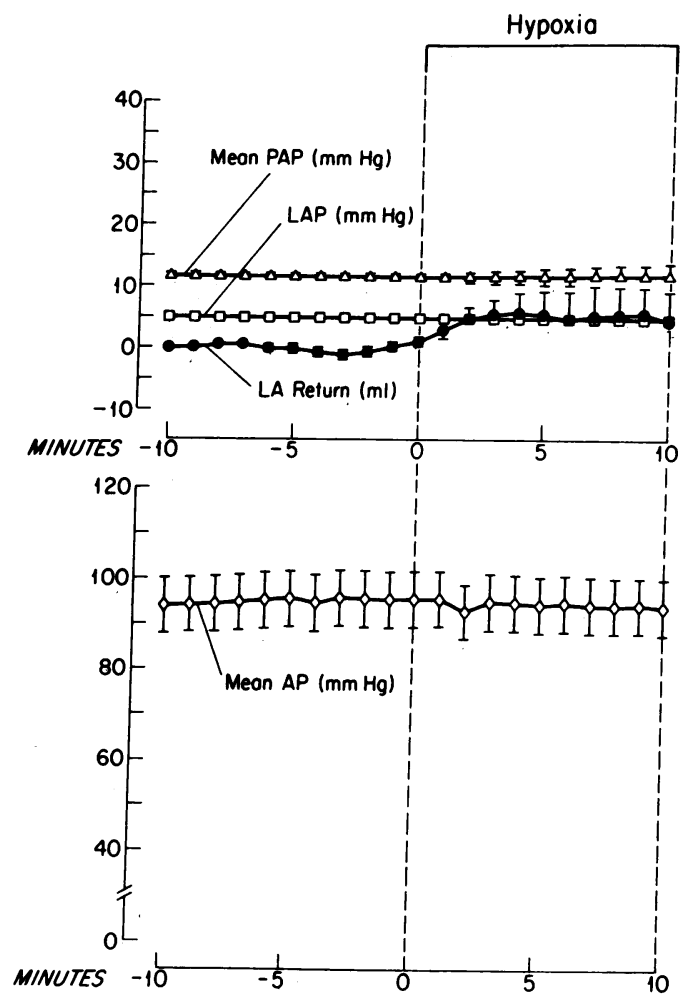

Figure 9. Mean data from all 15 trials of alveolar hypoxia in six dogs with the bronchial vessels divided. All values except LAP, which was held constant, are mean \pm SEM. Abbreviations as in Fig. 2. No recovery data are shown for the same reason as in Fig. 7. None of the changes are statistically significant.

changes of this magnitude could occur on the basis of changes in vascular capacity alone, especially in the absence of any changes in the principal determinants of pulmonary blood volume, namely vascular and airway pressures. By the same reasoning, the increased LA return could not be the result of decreasing extravascular fluid content, because the total fluid content of the lung is also of the same order of magnitude as the extra LA return after prolonged hypoxia. Moreover, several investigators (30-32) have reported that alveolar hypoxia causes no change in lung extravascular fluid content.

Second, the time course of the change in LA return is more consistent with a change in flow than a change in volume. Blood flow from the LA increased with the onset of hypoxia and remained at a roughly constant increased rate throughout the period of hypoxia. One would expect that, in response to a "square wave" stimulus such as hypoxia, the time course of a change in intravascular volume would be a hyperbolic sort of curve that would over time become parallel to the control curve. To produce the response actually seen in our studies, the compliance vessels would have to be pushing volume out at a constant rate, i.e., constantly constricting more and more throughout the period of a constant level of hypoxia.

Third, the persistent LA return after interruption of PA inflow can be due only to systemic-pulmonary shunting. Though the systemic pressure-pulmonary pressure relationships are different with pulmonary inflow arrested, the fact that the associated pulmonary drainage was greater during alveolar hypoxia than during control indicates that an increase in bronchopulmonary 
Table VI. Persistent LA Flow after Stopping the PA and LA Pumps (Bronchopulmonary Anastomotic Flow): Effects of Alveolar Hypoxia with and without Ibuprofen

\begin{tabular}{|c|c|c|c|c|c|c|}
\hline & \multicolumn{3}{|c|}{ Before ibuprofen } & \multicolumn{3}{|l|}{ After ibuprofen } \\
\hline & Control & Alveolar hypoxia & Percent difference & Control & Alveolar hypoxia & Percent difference \\
\hline & $\mathrm{ml} / \mathrm{min}$ & $\mathrm{ml} / \mathrm{min}$ & $\%$ & $\mathrm{ml} / \mathrm{min}$ & $\mathrm{ml} / \mathrm{min}$ & $\%$ \\
\hline $\operatorname{Dog} 1$ & 18 & 26 & +44 & 6 & 7 & +17 \\
\hline $\operatorname{Dog} 2$ & 20 & 25 & +25 & & & \\
\hline Dog 3 & 108 & 130 & +20 & 96 & 96 & 0 \\
\hline $\operatorname{Dog} 4$ & 90 & 100 & +11 & 30 & 28 & -7 \\
\hline Dog 5 & 18 & 26 & +44 & 10 & 9 & -10 \\
\hline Dog 6 & 60 & 80 & +33 & & & \\
\hline Mean \pm SEM & $52.3 \pm 16.3$ & $64.5 \pm 18.5$ & $29.5 \pm 5.4^{*}$ & $31.6 \pm 16.6 \ddagger$ & $30.4 \pm 16.8$ & $-5 \pm 6.8 \S$ \\
\hline
\end{tabular}

${ }^{*} P<0.05$. $\ddagger$ Significantly $(P<0.05)$ less than control before ibuprofen. $\S$ Not significant.

shunting occurred independent of any changes in pulmonary intra- and extravascular fluid content.

Finally, and most important, the increased LA return with hypoxia was eliminated entirely by surgical interruption of the bronchial vessels. One could suggest that such manipulations somewhow interfere with the reactivity of the pulmonary compliance vessels. However, the response of the pulmonary vasculature to infused drugs (e.g., Fig. 6) is unchanged by division of the bronchial vessels.

The increase in bronchopulmonary shunting must be a local effect of the alveolar hypoxia itself. Reflex and neural mechanisms have been ruled out by the occurrence of the effect despite ganglionic blockade and vagotomy. Systemic blood $\mathrm{PO}_{2}$ and $\mathrm{PCO}_{2}$ were maintained constant. The major hemodynamic determinants of bronchopulmonary shunt flow, namely aortic, PA, LA, and RA pressures were either held constant, or they changed in such a direction that would otherwise cause a decrease in bronchopulmonary flow. In fact, this last point demonstrates that the increased shunt must be due to an actual decrease in resistance to flow through the bronchopulmonary anastomoses.

The mechanism of the increase in bronchopulmonary shunt flow caused by alveolar hypoxia is not yet established. However, several aspects of the present studies suggest humoral mediation. The occurrence of systemic arterial dilatation beginning at just the time it takes blood from the pulmonary circulation to reach the systemic circuit in the present preparation suggests the liberation of a dilating substance from the hypoxic pulmonary vasculature. The fact that ibuprofen and indomethacin given before the onset of hypoxia can not only abolish the increase in LA return but also attenuate this systemic dilatation implicates dilating prostaglandins. One possibility is that alveolar hypoxia induces, or increases, production by the lung vasculature of one or more vasodilating prostaglandins, which not only dilate the bronchopulmonary vessels but other systemic vessels as well. The identity of which, if any, dilating prostaglandins are released during alveolar hypoxia remains to be documented. A recent report (33) has documented increased levels of prostaglandin $E_{2}$ in bronchopulmonary blood during cardiopulmonary bypass in humans; the state of aeration of the lungs during bypass in this latter study, i.e., whether they were left inflated or deflated, or whether they were ventilated, was not mentioned.

The fact that less systemic vasodilatation occurred with the bronchial vessels divided than with an intact bronchial circulation might suggest that the bronchial and/or bronchopulmonary anastomotic vessels themselves are the site of production of the hypothesized vasodilating agent. However, since the bronchial vessels provide the vasa vasorum of the pulmonary vasculature, their elimination could affect any metabolic processes-such as prostaglandin production-carried out in the walls of the pulmonary vessels themselves.

An initially surprising finding in the present study was the lack of significant PA vasoconstriction in our preparation in response to alveolar hypoxia. In both humans (34) and dogs (35-37) there is wide variation among individuals in the strength of the pulmonary hypoxic pressor response. It has been demonstrated in dogs that (1) resting pulmonary tone is increased by administration of prostaglandin synthesis inhibitors $(38,39)$ and that (2) the PA hypoxic pressor response which is initially absent or weak in individual animals can be restored by inhibitors of prostaglandin synthesis (35-37). The increase in baseline mean PA and systemic arterial pressures and the restoration of the hypoxic pressor response by ibuprofen and indomethacin in our studies corroborate these findings and suggest the presence, even in the control state, of a circulating prostaglandin vasodilating

Table VII. Persistent LA Flow after Stopping the PA and LA Pumps (Bronchopulmonary Anastomotic Flow): Effects of Alveolar Hypoxia with and without Indomethacin

\begin{tabular}{|c|c|c|c|c|c|c|}
\hline & \multicolumn{3}{|c|}{ Before indomethacin } & \multicolumn{3}{|c|}{ After indomethacin } \\
\hline & Control & Alveolar hypoxia & Percent difference & Control & Alveolar hypoxia & Percent difference \\
\hline & $\mathrm{ml} / \mathrm{min}$ & $\mathrm{ml} / \mathrm{min}$ & $\%$ & $\mathrm{ml} / \mathrm{min}$ & $\mathrm{ml} / \mathrm{min}$ & $\%$ \\
\hline Dog 23 & 26 & 40 & +53 & 12 & 14 & +16 \\
\hline Dog 24 & 14 & 20 & +42 & 12 & 10 & -16 \\
\hline
\end{tabular}


agent. It is possible that the use of extracorporeal circulation and/or nonpulsatile pulmonary perfusion contributed to the production of such an agent.

The association between the restoration of an active pulmonary hypoxic vasoconstrictor response with prostaglandin synthesis inhibition and the abolition of the hypoxia-induced increase in bronchopulmonary shunting might suggest a causal relationship between the two. At first glance this seems plausible, because, in general, an increase in PA pressure will tend to decrease bronchopulmonary shunt flow by increasing the "outflow pressure" of the anastomotic channels. However, the conclusion that the two phenomena are separate effects of prostaglandin inhibition is supported by several observations. First, it is generally agreed that hypoxic pulmonary vasoconstriction occurs at the level of the small muscular pulmonary "arterioles" (2), whereas the majority of the bronchopulmonary anastomoses are thought to be at the capillary level $(10,11)$; thus on anatomic grounds it could be concluded that hypoxic pulmonary vasoconstriction probably does not increase the outflow pressure of the bronchopulmonary shunts. Second, the gradual and progressive increase in PA pressure with hypoxia after prostaglandin administration (Figs. 7 and 8) should cause, using purely hemodynamic reasoning, a gradual and progressive decrease in bronchopulmonary flow; such an effect was not found. Finally, the hypoxia-induced increase in bronchopulmonary flow seen with pulmonary inflow arrested (Tables VI and VII) was abolished by prostaglandin inhibition. This last effect is, of course, independent of any changes in pulmonary artery pressure.

The finding that the LA return flow rate immediately after a period of alveolar hypoxia was actually less than the control rate, even after aortic pressure had recovered, is indicative of posthypoxic vasoconstriction of the bronchopulmonary anastomoses. This raises the interesting possibility that a vasoconstricting agent may be released, either during the period of alveolar hypoxia or upon recovery from hypoxia.

The magnitude of the increase in bronchopulmonary shunt flow seen in these studies, on the order of 3-4 ml/min, represents $\sim 20-50 \%$ of the total bronchopulmonary blood flow as measured by several other investigators $(9,13,17)$. With higher systemic pressure, the flow increase would be even larger (cf. Table V). Although one cannot extrapolate the absolute magnitude of the changes in bronchopulmonary shunt flow found in this study to the closed-chest, spontaneously breathing state, one would expect the changes in bronchopulmonary flow to be directionally similar. The amount of shunt flow in the present study would increase the bronchial contribution to anatomic right-to-left shunting, and thus to systemic desaturation, only marginally. Likewise it would not produce any substantial increase in LV filling. However, the increased shunt flow could be expected to improve the nutrition of, and especially oxygen delivery to, the lung parenchyma and the small airway and vessel walls in those areas involved by consolidation, alveolar edema, or atelectasis. Moreover, the dilating effects of acute alveolar hypoxia on the bronchopulmonary anastomoses may be involved in the initial steps in the development of the sometimes massive enlargement of the bronchial circulation seen in such chronic hypoxic states as bronchiectasis.

\section{Acknowledgments}

The authors are grateful to Luis J. Guerrero, Nina D. Wilson, Richard Wawrzynski, Ruth T. Crowley, John M. Ricci, Michael San Filippo, and Karen Calkins for their technical assistance, and to John B. Newell for his help with statistical analyses.

Dr. Warren was the Edward D. Churchill Research Fellow of the Department of Surgery of the Massachusetts General Hospital during the time this study was performed. The study was supported in part by U. S. Public Health Service National Institutes of Health grants HL32796 and HL-29817.

\section{References}

1. Barer, G. R. Active control of the pulmonary circulation. In Pulmonary Circulation in Health and Disease. 1980. G. Cumming and G. Bonsignore, editors. Plenum Press, New York. 81-104.

2. Dawson, C. A. 1984. Role of pulmonary vasomotion in physiology of the lung. Physiol. Rev. 64:544-616.

3. Shedd, D. P., R. D. Alley, and G. E. Lindskog. 1951. Observations on the hemodynamics of bronchial-pulmonary vascular communications. J. Thorac. Surg. 22:537-548.

4. Williams, M. H., and E. J. Towbin. 1955. Magnitude and time of development of the collateral circulation to the lung after occlusion of the left pulmonary artery. Circ. Res. 3:422-424.

5. Salisbury, P. F., P. Weil, and D. State. 1957. Factors influencing collateral blood flow to the dog's lung. Circ. Res. 5:303-309.

6. Auld, P. A. M., A. M. Rudolph, and R. J. Golinko. 1960. Factors affecting bronchial collateral flow in the dog. Am. J. Physiol. 198:11661170.

7. Horisberger, B., and S. Rodbard. 1960. Direct measurement of bronchial arterial flow. Circ. Res. 8:1149-1156.

8. Aramenidia, P., J. Martinez, and D. M. Aviado. 1962. Responses of the bronchial veins in a heart-lung-bronchial preparation. Circ. Res. 10:3-10.

9. Modell, H. I., K. Beck, and J. Butler. 1981. Functional aspects of canine bronchial-pulmonary vascular communications. J. Appl. Physiol. 50:1045-1051.

10. Pump, K. K. 1972. Distribution of bronchial arteries in the human lung. Chest 62:447-451.

11. McLaughlin, R. F. 1983. Bronchial artery distribution in various mammals and in humans. Am. Rev. Respir. Dis. 128:S57-S58.

12. Bruner, H. D., and C. F. Schmidt. 1947. Blood flow in the bronchial artery of the anesthetized dog. Am. J. Physiol. 148:648-666.

13. Aviado, D. M., M. de B. Daly, C. Y. Lee, and C. F. Schmidt. 1961. The contribution of the bronchial circulation to the venous admixture in pulmonary venous blood. J. Physiol. (Lond.). 155:602-622.

14. Baile, E. M., R. K. Albert, W. Kirk, S. Lakshaminarayan, B. J. Wiggs, and P. D. Pare. 1984. Positive end-expiratory pressure decreases bronchial blood flow in the dog. J. Appl. Physiol. 56:1289-1293.

15. Wagner, E. M., M. E. Bollinger, and E. R. Bleecker. 1985. Bronchial artery pressure-flow relationships. Fed. Proc. 44:7861. (Abstr.)

16. Berry, J. L., and I. de B. Daly. 1932. The relation between the pulmonary and bronchial vascular systems. Proc. R. Soc. Lond. B Biol. Sci. 109:319.

17. Martinez, J., R. Castro, and D. M. Aviado. 1961. Local and reflex effects of bronchial arterial injection of drugs. J. Pharmacol. Exp. Ther. 133:295-303.

18. Lilker, E. S., and E. J. Nagy. 1975. Gas exchange in the pulmonary collateral circulation of dogs. Am. Rev. Respir. Dis. 112:615-620.

19. Charan, N. B., S. Lakshminarayan, R. K. Albert, W. Kirk, and J. Butter. 1981. Hypoxemia and hypercarbia increase bronchial blood flow. Clin. Res. 29:67A. (Abstr.)

20. Magno, M. G., and A. P. Fishman. 1982. Origin, distribution, and blood flow of bronchial circulation in anesthetized sheep. J. Appl. Physiol. 53:272-279.

21. Malik, A. B., and S. E. Tracy. 1980. Bronchovascular adjustments after pulmonary embolism. J. Appl. Physiol. 49:476-481.

22. Baile, E. M., and P.D. Pare. 1983. Response of the bronchial circulation to acute hypoxemia and hypercarbia in the dog. J. Appl. Physiol. 55:1474-1479. 
23. Snedecor, G. W., and W G. Cochran. 1971. Statistical Methods. 6th edition. Iowa State University Press, Ames, IA. 104-105, 153-154.

24. Sackner, M. A., D. H. Will, and A. B. Dubois. 1966. The site of pulmonary vasomotor activity during hypoxia or serotonin administration. J. Clin. Invest. 45:112-121.

25. Piiper; J. 1970. Attempts to determine volume, compliance, and resistance to flow of pulmonary vascular compartments. Prog. Respir. Res. 5:40-52.

26. Maseri, A., P. Caldini, P. Harward, R. C. Joshi, S. Permutt, and K. L. Zierler. 1972. Determinants of pulmonary vascular volume. Recruitment versus distensibility. Circ. Res. 31:218-228.

27. Thorvaldson, J., A. Ilebekk; S. Leraand, and F. Kiil. 1984. Determinants of pulmonary blood volume. Effects of acute changes in pulmonary vascular pressures and flow. Acta Physiol. Scand. 121:45-56.

28. Glazier, J. B., and J. F. Murray. 1971. Sites of pulmonary vasomotor reactivity in the dog during alveolar hypoxia and serotonin and histamine infusion. J. Clin. Invest. 50:2550-2558.

29. Dawson, C. A., T. E. Forrester, and L. H. Hamilton. 1975. Effects of hypoxia and histamine infusion on lung blood volume. J. Appl. Physiol. 38:811-816.

30. Haddy, F. J., G. S. Campbell, and M. B. Visscher. 1950. Pulmonary vascular pressures in relation to edema production by airway resistance and plethora in dogs. Am. J. Physiol. 161:336-341.

31. Nicoloff, D. M., H. M. Ballin, and M. B. Visscher. 1969. Hypoxia and edema of the perfused isolated canine lung. Proc. Soc. Exp. Biol. Med. 131:22-26.

32. Aarseth, P., L. Bjertnaes, and J. Karlsen. 1980. Changes in blood volume and extravascular water content in isolated perfused rat lungs during ventilation hypoxia. Acta Physiol. Scand. 109:61-67.

33. Lajos, T. Z., J. Venditti, and R. Venuto: 1985. Hemodynamic consequences of bronchial flow during cardiopulmonary bypass. $J$. Thorac. Cardiovasc. Surg. 89:934-941.

34. Grover, R. F., W. W. Wagner, Jr., I. F. McMurtry, and J. T. Reeves. 1983. Pulmonary circulation. Handb. Physiol. (Sect. 2, Pt. 1.) 3:111-115.

35. Alexander, J. M., M. D. Nyby, and K. A. Jasberg. 1977. Prostaglandin synthesis inhibition restores hypoxic pulmonary vasoconstriction. J. Appl. Physiol. 42:903-908.

36. Hales, C. A., E. T. Rouse, and J. L. Slate. 1978. Influence of aspirin and indomethacin on variability of alveolar hypoxic vasoconstriction. J. Appl. Physiol. 45:33-39.

37. Siefkin, A. D., and G. H. Parsons. 1981. Hypoxic pulmonary vasoconstriction: nonresponse reversed by aspirin. Clin. Res. 29:70A. (Abstr.)

38. Hyman, A. L., E. W. Spannhake, and P. J. Kadowitz. 1978. Prostaglandins and the lung. Am. Rev. Respir. Dis. 117:111-136.

39. Murray, P. A., H. S. Geller, H. M. Goll, and D. P. Nyhan. 1985. Cyclooxygenase pathway inhibition results in active pulmonary vasoconstriction in conscious dogs. Circ. 72:III-705a. (Abstr.) 